Check for updates

Cite this: J. Mater. Chem. A, 2018, 6, 2337

Received 13th October 2017 Accepted 25th December 2017

DOI: $10.1039 / \mathrm{c} 7 \mathrm{ta0} 0001 \mathrm{c}$

rsc.li/materials-a

\section{MXenes/graphene heterostructures for Li battery applications: a first principles study $\dagger$}

\author{
Yierpan Aierken, ${ }^{\text {a }}$ Cem Sevik, ${ }^{\text {b }}$ Oğuz Gülseren, ${ }^{c}$ François M. Peeters ${ }^{a}$ \\ and Deniz Çakır (iD)*ad
}

MXenes are the newest class of two-dimensional (2D) materials, and they offer great potential in a wide range of applications including electronic devices, sensors, and thermoelectric and energy storage materials. In this work, we combined the outstanding electrical conductivity, that is essential for battery applications, of graphene with MXene monolayers $\left(\mathrm{M}_{2} \mathrm{CX}_{2}\right.$ where $\mathrm{M}=\mathrm{Sc}, \mathrm{Ti}, \mathrm{V}$ and $\left.\mathrm{X}=\mathrm{OH}, \mathrm{O}\right)$ to explore its potential in Li battery applications. Through first principles calculations, we determined the stable stacking configurations of $\mathrm{M}_{2} \mathrm{CX}_{2}$ /graphene bilayer heterostructures and their Li atom intercalation by calculating the Li binding energy, diffusion barrier and voltage. We found that: (1) for the ground state stacking, the interlayer binding is strong, yet the interlayer friction is small; (2) Li binds more strongly to the O-terminated monolayer, bilayer and heterostructure MXene systems when compared with the $\mathrm{OH}$ terminated MXenes due to the $\mathrm{H}^{+}$induced repulsion to the $\mathrm{Li}$ atoms. The binding energy of Li decreases as the $\mathrm{Li}$ concentration increases due to enhanced repulsive interaction between the positively charged $\mathrm{Li}$ ions; (3) $\mathrm{Ti}_{2} \mathrm{CO}_{2}$ /graphene and $\mathrm{V}_{2} \mathrm{CO}_{2}$ /graphene heterostructures exhibit large $\mathrm{Li}$ atom binding energies making them the most promising candidates for battery applications. When fully loaded with $\mathrm{Li}$ atoms, the binding energy is $-1.43 \mathrm{eV}$ per $\mathrm{Li}$ atom and $-1.78 \mathrm{eV}$ per $\mathrm{Li}$ atom for $\mathrm{Ti}_{2} \mathrm{CO}_{2} /$ graphene and $\mathrm{V}_{2} \mathrm{CO}_{2}$ /graphene, respectively. These two heterostructures exhibit a nice compromise between storage capacity and kinetics. For example, the diffusion barrier of $\mathrm{Li}$ in $\mathrm{Ti}_{2} \mathrm{CO}_{2} /$ graphene is around $0.3 \mathrm{eV}$ which is comparable to that of graphite. Additionally, the calculated average voltages are $1.49 \mathrm{~V}$ and $1.93 \mathrm{~V}$ for $\mathrm{Ti}_{2} \mathrm{CO}_{2}$ /graphene and $\mathrm{V}_{2} \mathrm{CO}_{2}$ /graphene structures, respectively; (4) a small change in the in-plane lattice parameters $(<1 \%)$, interatomic bond lengths and interlayer distances $(<0.5 \AA)$ proves the stability of the heterostructures against $\mathrm{Li}$ intercalation, and the impending phase separation into constituent layers and capacity fading during charge-discharge cycles in real battery applications; (5) as compared to bare $\mathrm{M}_{2} \mathrm{CX}_{2}$ bilayers, $\mathrm{M}_{2} \mathrm{CX}_{2}$ /graphene heterostructures have lower molecular mass, offering high storage capacity; (6) the presence of graphene ensures good electrical conductivity that is essential for battery applications. Given these advantages, $\mathrm{Ti}_{2} \mathrm{CO}_{2} /$ graphene and $\mathrm{V}_{2} \mathrm{CO}_{2} /$ graphene heterostructures are predicted to be promising for lithium-ion battery applications.

\section{Introduction}

Lithium ion batteries (LIBs) are widely used for electrochemical energy storage in electrical vehicles and portable electronic

\footnotetext{
${ }^{a}$ Department of Physics, University of Antwerp, Groenenborgerlaan 171, 2020 Antwerpen, Belgium. E-mail: yierpan.aierken@uantwerpen.be; francois.peeters@ uantwerpen.be

${ }^{b}$ Department of Mechanical Engineering, Faculty of Engineering, Anadolu University, Eskisehir, TR 26555, Turkey.E-mail: csevik@anadolu.edu.tr

'Department of Physics, Bilkent University, Ankara 06800, Bilkent, Turkey. E-mail: gulseren@fen.bilkent.edu.tr

${ }^{d}$ Department of Physics and Astrophysics, University of North Dakota, Grand Forks, North Dakota 58202, USA. E-mail: deniz.cakir@und.edu

$\dagger$ Electronic supplementary information (ESI) available: Information about the binding energies of other stacking types and other Li absorption sites. See DOI: 10.1039/c7ta09001c
}

devices such as cell phones. The speed of development of these state of the art products mostly hinges on the progress in battery technology. The energy density and rate capability of both LIBs and sodium ion batteries (NIBs) are currently insufficient to satisfy customers' needs. Therefore, the demand for metal based new generation batteries that have large reversible energy/power capacity, good cycling stability and long life span is growing. Recently, rechargeable batteries based on $2 \mathrm{D}$ materials have received great attention because of the promising potential of $2 \mathrm{D}$ materials as anode materials with enhanced gravimetric and volumetric energy densities which are a key challenge to obtain in current rechargeable ion battery technology. For instance $\mathrm{Mo}_{2} \mathrm{C}$ was shown to exhibit much better electrochemical properties in lithium-ion battery applications. ${ }^{1}$ Moreover, other 2D layered materials such as transition metal dichalcogenides, ${ }^{2,3}$ black phosphorus, ${ }^{4,5}$ and MXenes 
(with $\mathrm{M}=\mathrm{Ti}, \mathrm{V}, \mathrm{Nb}$, Mo and $\mathrm{X}=\mathrm{C}, \mathrm{N})^{\mathbf{6 - 1 1}}$ have also been widely investigated because of their high energy storage density and high rate capacity. However, experimental studies have shown that single type layered nanosheets inevitably restack during the cycling process, resulting in a rapid capacity fading and poor rate performance.

Therefore, current interest has been directed towards heterostructured $^{\mathbf{1 2 , 1 3}} 2 \mathrm{D}$ materials. A clever design of vertical heterostructures from different $2 \mathrm{D}$ materials is expected to be beneficial for rapid electron transport and accelerated cation transport in electrodes, and thus is expected to improve the rate performance in current battery technology. ${ }^{13}$ In addition, the negligible volumetric changes of TMDCs and MXenes in particular in lithiation/de-lithiation processes, such that there is only a $5 \%$ in-plane lattice expansion in the $\mathrm{Mo}_{2} \mathrm{C}$ lattice caused by $\mathrm{Li}$ intercalation, ${ }^{\mathbf{1 4}}$ can minimize the intrinsic volumetric changes during charging/discharging processes which prolongs the cycling lifetime of rechargeable batteries. Furthermore, combining different 2D materials is a promising way to adjust the interlayer distance to accommodate much larger (i.e. $\mathrm{Na}^{+}$) and more polarized (i.e. $\mathrm{Mg}^{2+}$ ) ions. For instance, a lithium-ion capacity in excess of $750 \mathrm{~mA} \mathrm{~h} \mathrm{~g}^{-1}$ (ref. 15) has already been demonstrated for batteries with MXene electrodes, optimized with CNTs.

To this end, we systematically investigated Li intercalation in vertical (van der Waals) heterostructures of MXenes and graphene for rechargeable battery applications. We only considered MXenes functionalized with $\mathrm{OH}$ and $\mathrm{O}$, since experimentally synthesized MXenes are often functionalized with various radicals due to chemical exfoliation. Also, several previous studies showed that F-functionalized MXenes are not as stable as $\mathrm{O}$ - or $\mathrm{OH}$-functionalized ones, ${ }^{\mathbf{1 6}}$ and the $\mathrm{F}$ group results in lower capacities and very high Li diffusion barriers as compared to $\mathrm{O}$ terminated MXenes. ${ }^{16,17}$ On the other hand, MXenes with low formula weights, such as $\mathrm{Ti}_{2} \mathrm{C}, \mathrm{Nb}_{2} \mathrm{C}, \mathrm{V}_{2} \mathrm{C}$ and $\mathrm{Sc}_{2} \mathrm{C}$, have been found to be the most promising ${ }^{18}$ materials in battery applications due to their theoretically stated high gravimetric capacity, which represents the amount of charge that can be stored per gram of material. Therefore, we considered only $\mathrm{M}_{2} \mathrm{CX}_{2}$ (where $\mathrm{M}=\mathrm{Sc}$, Ti, $\mathrm{V}$ and $\mathrm{X}=\mathrm{OH}, \mathrm{O}$ ) monolayers in this study. $\mathrm{V}_{2} \mathrm{CX}_{2}$ is particularly important since it shows the largest $\mathrm{Li}^{+}$capacity of all MXenes tested under similar conditions. ${ }^{19}$ Another advantage is that, compared to bilayer $\mathrm{M}_{2} \mathrm{CX}_{2}, \mathrm{M}_{2} \mathrm{CX}_{2} /$ graphene heterostructures have a much smaller weight, offering much larger storage capacity. Finally, stacking dissimilar materials with different electronic conductivities together can be a promising way to increase the conductivity of individual layers. This was experimentally shown for graphene/ MXene heterostructures. ${ }^{\mathbf{2 0}}$ For instance, the transport properties (both electrical conductance and Hall carrier mobility) of $\mathrm{Ti}_{3} \mathrm{C}_{2} \mathrm{X}_{x}$ were found to be highly enhanced when mixed with graphene.

We introduce the following nomenclature in the following sections: $\mathrm{M}$ stands for the transition metal in MXenes; X stands for the functionalization group, i.e. $\mathrm{OH}$ or $\mathrm{O}$; $\mathrm{Gr}$ stands for graphene; $\mathrm{Li}$ is the intercalated $\mathrm{Li}$ atom (unless the concentration is stated it means only single $\mathrm{Li}$ atom intercalation); monolayer and bilayer are denoted with mono- or bi-prefixes. For instance: bi- $\mathrm{Ti}_{2} \mathrm{CO}_{2}+\mathrm{Li}$ stands for bilayer $\mathrm{Ti}_{2} \mathrm{CO}_{2}$ with a single $\mathrm{Li}$ atom intercalation, and $\mathrm{Ti}_{2} \mathrm{CO}_{2}+\mathrm{Gr}+\mathrm{Li}$ stands for the heterostructure of $\mathrm{Ti}_{2} \mathrm{CO}_{2}$ on graphene with intercalation of a single Li atom.

\section{Computational details}

The physical properties of the considered systems were obtained by density functional theory based simulations as implemented in the Vienna $a b$ initio Simulation Package (VASP). ${ }^{21-24}$ In these simulations, a plane-wave basis set with a $500 \mathrm{eV}$ energy cut-off, the projected augmented wave (PAW) potentials ${ }^{25,26}$ with the generalized gradient approximation (GGA) within the Perdew-Burke-Ernzerhof (PBE) formulation, ${ }^{27,28}$ and a $7 \times 7 \times 1$ up to $11 \times 11 \times 1 k$-point mesh (depending on the size of the supercell) were used. Since we dealt with weakly interacting systems, weak van der Waals interactions were taken into account using the DFT-D3 method of Grimme et al. ${ }^{29}$ including Becke-Johnson damping. Lattice vectors perpendicular to the $2 \mathrm{D}$ plane were fixed as $30 \AA$ for all the simulations. A $10^{-5} \mathrm{eV}$ energy and a $10^{-3} \mathrm{eV} \AA^{-1}$ force convergence criteria were set to achieve the ground state structure and its energy. Charge transfer between Li atoms and the host systems were calculated via Bader analysis. ${ }^{30-33}$

We calculated diffusion barriers for $\mathrm{Li}$ ions using the climbing-image nudge elastic (cNEB) method as implemented in the VASP transition state tools. ${ }^{34,35}$ The cNEB method is an efficient method to determine the minimum energy diffusion path between two given positions. We used at least 7 images, including the initial and final positions, for cNEB calculations. The atomic positions and energy of the images were then relaxed until the absolute value of the largest force orthogonal to the path is smaller than $0.01 \mathrm{eV}^{-1}$.

\section{Results}

\subsection{Heterostructure stacking types}

First of all, we constructed MXene-graphene heterostructures by considering supercells such that we have a minimum lattice mismatch between the layers. Therefore, heterostructures with a $3 \times 3$ supercell of $\mathrm{Sc}_{2} \mathrm{CO}_{2}$ or $\mathrm{Sc}_{2} \mathrm{C}(\mathrm{OH})_{2}$ with a $4 \times 4$ supercell of graphene, a $4 \times 4$ supercell of $\mathrm{Ti}_{2} \mathrm{CO}_{2}$ or $\mathrm{Ti}_{2} \mathrm{C}(\mathrm{OH})_{2}$ with a $5 \times$ 5 supercell of graphene, and a $5 \times 5$ supercell of $\mathrm{V}_{2} \mathrm{CO}_{2}$ or $\mathrm{V}_{2} \mathrm{C}(\mathrm{OH})_{2}$ with a $6 \times 6$ supercell of graphene were constructed; see Fig. 1 for a representative example. In order to find out the ground state stacking type of these $\mathrm{M}_{2} \mathrm{CX}_{2}+\mathrm{Gr}$ heterostructures, we calculated the binding energy of possible stacking configurations by shifting the $\mathrm{M}_{2} \mathrm{CX}_{2}$ layer over the unit cell of graphene on a uniform mesh; see the ESI $\dagger$ for details. In the course of these simulations, each layer in the heterostructure is regarded as rigid where only the interlayer distance is allowed to relax. The corresponding binding energy per atom, $E_{\mathrm{b}}$, was calculated as follows:

$$
E_{\mathrm{b}}=\frac{1}{N}\left[E\left(\mathrm{M}_{2} \mathrm{CX}_{2}+\mathrm{Gr}\right)-E\left(\mathrm{M}_{2} \mathrm{CX}_{2}\right)-E(\mathrm{Gr})\right]
$$




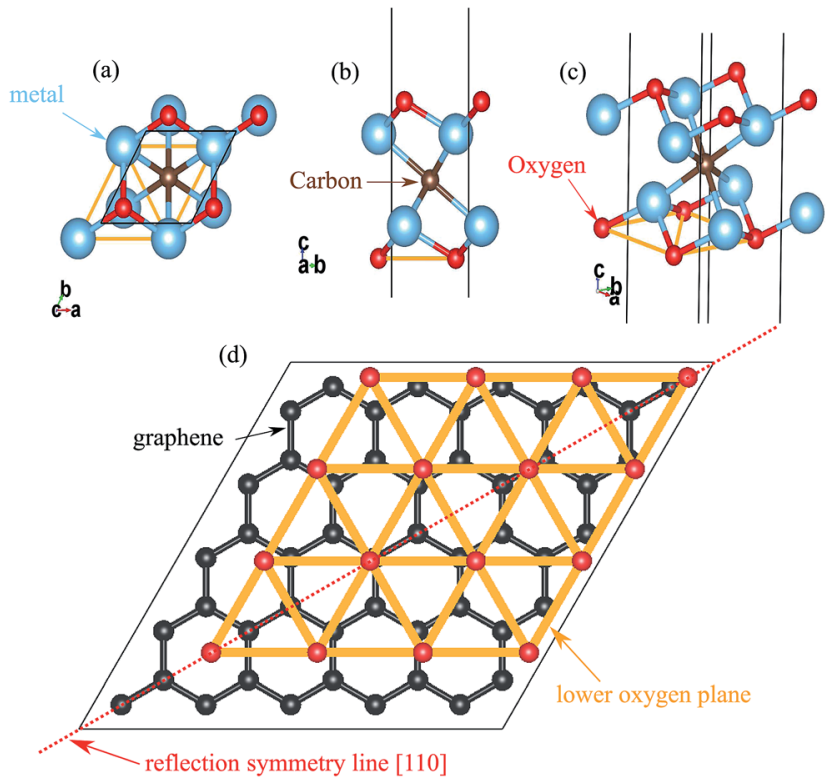

Fig. 1 A typical example structure of mono- $\mathrm{Ti}_{2} \mathrm{CO}_{2}$ with the (a) top view, (b) side view, and (c) tilted view. (d) Simplified example of the $\mathrm{M}_{2} \mathrm{CX}_{2} / \mathrm{Gr}$ heterostructure in its ground state stacking.

where $E\left(\mathrm{M}_{2} \mathrm{CX}_{2}+\mathrm{Gr}\right), E\left(\mathrm{M}_{2} \mathrm{CX}_{2}\right)$ and $E(\mathrm{Gr})$ are the total energy of $\mathrm{M}_{2} \mathrm{CX}_{2}+\mathrm{Gr}$, mono- $\mathrm{M}_{2} \mathrm{CX}_{2}$ and $\mathrm{Gr}$, respectively. $N$ is the total number of atoms in the supercell. In Table 1, the calculated $E_{\mathrm{b}}$ and the interlayer distance for $\mathrm{M}_{2} \mathrm{CX}_{2}+\mathrm{Gr}$ are given for all the considered systems. The results for bilayer graphene are also given as a reference. The interlayer binding energy and the distance of $\mathrm{AB}$ stacked bilayer graphene are $24 \mathrm{meV}$ per atom and $3.28 \AA$, respectively. Our calculations agree very well with

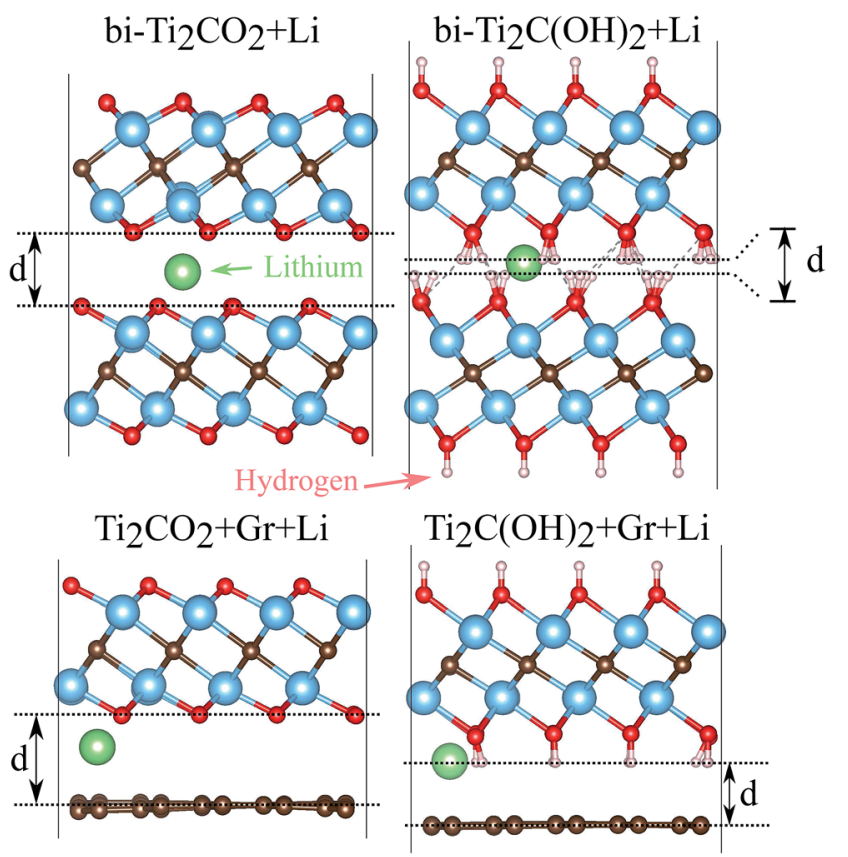

Fig. 2 The optimized location of single Li atoms in different structures and the definition of the interlayer distance $d$. a recent study in which quantum Monte Carlo simulations predicted an $18 \mathrm{meV}$ per atom binding energy and $3.38 \AA$ interlayer separation for bilayer graphene. ${ }^{36}$ The calculated binding energies (i.e. $E_{\mathrm{b}}$ ) are negative for all the considered heterostructures, demonstrating the stability of each system against phase separation. The magnitude of $E_{\mathrm{b}}$ for the ground state stacking in MXene oxides/graphene is comparable to that of bilayer graphene, whereas the hydroxides/graphene are slightly more strongly bonded due to the extra hydrogen bonds. The differences in binding energy among different MXenes that have the same functionalization group are negligible.

\subsection{Single Li intercalation and its binding energy}

Using the calculated ground state stacking types of all the $\mathrm{M}_{2} \mathrm{CX}_{2}+\mathrm{Gr}$ heterostructures, we investigated the Li intercalation in these structures. To systematically uncover the potential of $\mathrm{M}_{2} \mathrm{CX}_{2}+\mathrm{Gr}$ heterostructures for battery applications, we also considered Li intercalation on mono- $\mathrm{M}_{2} \mathrm{CX}_{2}$, within bi- $\mathrm{M}_{2} \mathrm{CX}_{2}$ and within bi-Gr. These additional reference calculations were performed with the same system dimensions, or equivalently the same $\mathrm{Li}$ atom concentration, as in the corresponding heterostructures.

Previous studies ${ }^{37-39}$ pointed out that the strongest binding of Li atoms occurs for bilayer heterostructures. They reported a non-binding character of $\mathrm{Li}$ atoms on the surface of few-layer graphene. Therefore, in this study, we limited ourselves to intercalation between $\mathrm{M}_{2} \mathrm{CX}_{2}$ and graphene. In addition, inspired by the previous study $^{40}$ on the location of the $\mathrm{Li}$ absorption site in $\mathrm{M}_{2} \mathrm{CX}_{2}$ multilayer systems, we found that the intercalated Li atom is bound close to the $\mathrm{M}_{2} \mathrm{CX}_{2}$ layer and far from graphene, and it resides between three $\mathrm{O}$ atoms. Thus, each formula unit of $\mathrm{M}_{2} \mathrm{CX}_{2}$ in the heterostructure can accommodate one $\mathrm{Li}$ atom. Additional $\mathrm{Li}$ atoms occupy the same position in other unit cells, as shown in Fig. 3. Note that the ground state stacking has reflection symmetry, and therefore we

Table 1 A comparison of different MXene systems: monolayer, bilayer, and heterostructure. $d$ is the interlayer distance and is defined as shown in Fig. 2. $E_{\mathrm{b}}$ is the binding energy of the system with respect to its components, e.g. the bilayer with respect to monolayers. Only the ground state stacking of $\mathrm{M}_{2} \mathrm{CX}_{2}+\mathrm{Gr}$ is reported

\begin{tabular}{|c|c|c|c|}
\hline Material & Structure & $d(\AA)$ & $E_{\mathrm{b}}(\mathrm{eV}$ per atom $)$ \\
\hline \multirow[t]{2}{*}{ Graphene } & bi-Gr (AB) & 3.277 & -0.024 \\
\hline & bi-Gr (AA) & 3.325 & -0.020 \\
\hline \multirow[t]{2}{*}{$\mathrm{Sc}_{2} \mathrm{CO}_{2}$} & bi-Sc $\mathrm{CO}_{2}$ & 2.294 & -0.029 \\
\hline & $\mathrm{Sc}_{2} \mathrm{CO}_{2}+\mathrm{Gr}$ & 3.067 & -0.022 \\
\hline \multirow[t]{2}{*}{$\mathrm{Sc}_{2} \mathrm{C}(\mathrm{OH})_{2}$} & $\mathrm{bi}^{-S c} \mathrm{c}_{2} \mathrm{C}(\mathrm{OH})_{2}$ & 0.598 & -0.025 \\
\hline & $\mathrm{Sc}_{2} \mathrm{C}(\mathrm{OH})_{2}+\mathrm{Gr}$ & 2.191 & -0.027 \\
\hline \multirow[t]{2}{*}{$\mathrm{Ti}_{2} \mathrm{CO}_{2}$} & bi- $\mathrm{Ti}_{2} \mathrm{CO}_{2}$ & 2.396 & -0.027 \\
\hline & $\mathrm{Ti}_{2} \mathrm{CO}_{2}+\mathrm{Gr}$ & 3.000 & -0.018 \\
\hline \multirow[t]{2}{*}{$\mathrm{Ti}_{2} \mathrm{C}(\mathrm{OH})_{2}$} & bi-Ti ${ }_{2} \mathrm{C}(\mathrm{OH})_{2}$ & 0.399 & -0.024 \\
\hline & $\mathrm{Ti}_{2} \mathrm{C}(\mathrm{OH})_{2}+\mathrm{Gr}$ & 2.097 & -0.034 \\
\hline \multirow[t]{2}{*}{$\mathrm{V}_{2} \mathrm{CO}_{2}$} & $\mathrm{bi}-\mathrm{V}_{2} \mathrm{CO}_{2}$ & 2.394 & -0.025 \\
\hline & $\mathrm{V}_{2} \mathrm{CO}_{2}+\mathrm{Gr}$ & 2.867 & -0.022 \\
\hline \multirow[t]{2}{*}{$\mathrm{V}_{2} \mathrm{C}(\mathrm{OH})_{2}$} & bi- $\mathrm{V}_{2} \mathrm{C}(\mathrm{OH})_{2}$ & 0.398 & -0.011 \\
\hline & $\mathrm{V}_{2} \mathrm{C}(\mathrm{OH})_{2}+\mathrm{Gr}$ & 2.779 & -0.035 \\
\hline
\end{tabular}




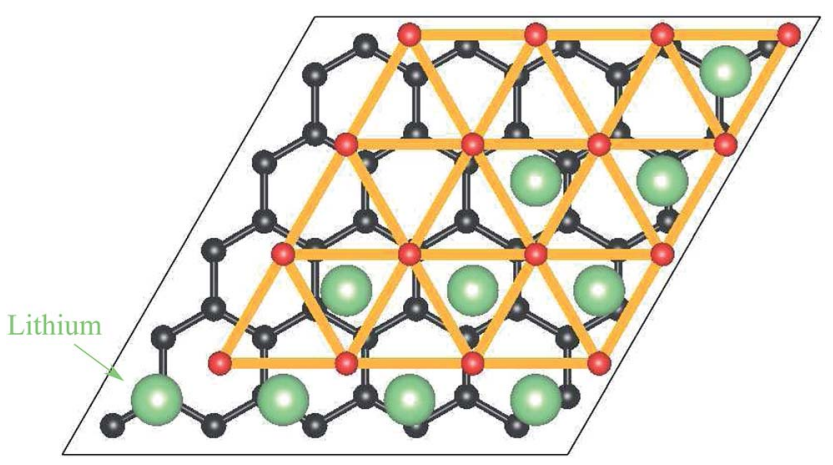

Fig. 3 Locations of $\mathrm{Li}$ atoms intercalated in the $\mathrm{Ti}_{2} \mathrm{CO}_{2}+\mathrm{Gr}$ heterostructure.

may limit ourselves to investigate Li positions only on one side of the symmetry line [110] for single Li absorption. A strong binding between $\mathrm{Li}$ and the $\mathrm{M}_{2} \mathrm{CX}_{2}+\mathrm{Gr}$ bilayer is necessary to avoid the formation of metallic lithium, which improves the safety and reversibility of lithium-ion batteries. Therefore, we need to make sure that the Li binding energy is as large as possible. We calculated all the possible adsorption sites between the two layers; see the ESI $\uparrow$ for details.
The binding energy, $E_{\mathrm{b}}^{\mathrm{Li}}$, for $\mathrm{Li}$ intercalated systems is defined through the following equation:

$$
E_{\mathrm{b}}^{\mathrm{Li}}=\frac{1}{x}[E(\text { with } x \mathrm{Li})-E(\text { without } \mathrm{Li})-x E(\mathrm{Li})],
$$

where $E$ (with $x \mathrm{Li}$ ) and $E$ (without $\mathrm{Li}$ ) are the total energies of the system with and without $x \mathrm{Li}$ atoms, respectively. $E(\mathrm{Li})$ is the total energy of a Li atom in its most stable bcc bulk structure. Our calculation gives a single $\mathrm{Li}$ atom total energy of $-0.30 \mathrm{eV}$ and a Li bcc phase total energy of $-2.08 \mathrm{eV}$ per atom, and therefore, the cohesive energy for Li atoms in the bcc phase is $-1.79 \mathrm{eV}$ per atom. The optimized lattice constant is $3.30 \AA$. These results are in agreement with previous studies. ${ }^{41,42}$ Here, a more negative binding energy indicates a more favorable exothermic binding of Li. We also included the vdW interaction in the calculation of Li bulk energy. We determined the vdW interaction in the bcc Li by taking the difference of the total energy with vdW correction and without it. This gives us 170 meV per atom vdW interaction energy, which is small as compared to the typical binding energies reported in this study, yet we still included it for more accurate determination.

In Table 2, the results for different materials are shown in three promising systems. For comparison, we also calculated $\mathrm{Li}$ intercalation in $\mathrm{AA}$ and $\mathrm{AB}$ stacked graphene bilayers. While the

Table 2 A comparison of different MXene systems: monolayer, bilayer, and heterostructure with Li intercalation. $d$ is the interlayer distance and is defined as shown in Fig. 2. $E_{\mathrm{b}}^{\mathrm{L} i}$ is the binding energy of a single Li atom. Only the largest binding energy of Li atoms is reported, i.e. ground state adsorption site. The charge transfer from a Li atom to a heterostructure is in the units of e. For the consistency of the Li concentrations, all monolayer and bilayer systems use the same dimensions as in the corresponding heterostructures. Three different computational unit cell sizes for bi-Gr are presented to compare with the heterostructures with the corresponding size of $\mathrm{Gr}$

\begin{tabular}{|c|c|c|c|c|c|}
\hline Material & Structure & $d(\AA)$ & $E_{\mathrm{b}}^{\mathrm{Li}}(\mathrm{eV}$ per atom $)$ & $\begin{array}{l}\text { Li charge transfer } \\
(e)\end{array}$ & $\begin{array}{l}\text { Theoretical gravimetric capacity } \\
\left(\mathrm{mA} \mathrm{h} \mathrm{g}^{-1}\right)\end{array}$ \\
\hline \multirow[t]{4}{*}{ Graphene } & $4 \times 4$ bi-Gr $(\mathrm{AB})+\mathrm{Li}$ & 3.591 & 0.030 & 0.873 & \multirow[t]{4}{*}{-} \\
\hline & $4 \times 4$ bi-Gr $(\mathrm{AA})+\mathrm{Li}$ & 3.616 & -0.232 & 0.868 & \\
\hline & $5 \times 5$ bi-Gr $(\mathrm{AA})+\mathrm{Li}$ & 3.617 & -0.283 & 0.878 & \\
\hline & $6 \times 6$ bi-Gr $(\mathrm{AA})+\mathrm{Li}$ & 3.636 & -0.336 & 0.879 & \\
\hline \multirow[t]{3}{*}{$\mathrm{Sc}_{2} \mathrm{CO}_{2}$ (unstable) } & mono-Sc $\mathrm{CO}_{2}+\mathrm{Li}$ & - & -9.986 & 0.898 & 362.666 \\
\hline & bi-Sc $\mathrm{CO}_{2}+\mathrm{Li}$ & 1.791 & -32.646 & 0.902 & 190.267 \\
\hline & $\mathrm{Sc}_{2} \mathrm{CO}_{2}+\mathrm{Gr}+\mathrm{Li}$ & 2.874 & -19.885 & 0.887 & 229.850 \\
\hline \multirow[t]{3}{*}{$\mathrm{Sc}_{2} \mathrm{C}(\mathrm{OH})_{2}$} & mono-Sc ${ }_{2} \mathrm{C}(\mathrm{OH})_{2}+\mathrm{Li}$ & - & 0.048 & 0.869 & 357.776 \\
\hline & $\mathrm{bi}^{-S c_{2}} \mathrm{C}(\mathrm{OH})_{2}+\mathrm{Li}$ & 0.548 & -0.309 & 0.885 & 187.577 \\
\hline & $\mathrm{Sc}_{2} \mathrm{C}(\mathrm{OH})_{2}+\mathrm{Gr}+\mathrm{Li}$ & 2.278 & -0.941 & 0.877 & 227.876 \\
\hline \multirow[t]{3}{*}{$\mathrm{Ti}_{2} \mathrm{CO}_{2}$} & mono- $\mathrm{Ti}_{2} \mathrm{CO}_{2}+\mathrm{Li}$ & - & -1.870 & 0.912 & 348.926 \\
\hline & $\mathrm{bi}-\mathrm{Ti}_{2} \mathrm{CO}_{2}+\mathrm{Li}$ & 2.480 & -2.308 & 0.886 & 182.717 \\
\hline & $\mathrm{Ti}_{2} \mathrm{CO}_{2}+\mathrm{Gr}+\mathrm{Li}$ & 2.976 & -1.729 & 0.887 & 234.395 \\
\hline \multirow[t]{3}{*}{$\mathrm{Ti}_{2} \mathrm{C}(\mathrm{OH})_{2}$} & mono- $\mathrm{Ti}_{2} \mathrm{C}(\mathrm{OH})_{2}+\mathrm{Li}$ & - & 0.146 & 0.792 & 344.397 \\
\hline & bi- $\mathrm{Ti}_{2} \mathrm{C}(\mathrm{OH})_{2}+\mathrm{Li}$ & 0.599 & -0.431 & 0.879 & 180.235 \\
\hline & $\mathrm{Ti}_{2} \mathrm{C}(\mathrm{OH})_{2}+\mathrm{Gr}+\mathrm{Li}$ & 2.090 & -0.229 & 0.875 & 232.343 \\
\hline \multirow[t]{3}{*}{$\mathrm{V}_{2} \mathrm{CO}_{2}$} & mono- $\mathrm{V}_{2} \mathrm{CO}_{2}+\mathrm{Li}$ & - & -2.791 & 0.921 & 335.495 \\
\hline & $\mathrm{bi}-\mathrm{V}_{2} \mathrm{CO}_{2}+\mathrm{Li}$ & 2.500 & -3.573 & 0.887 & 175.365 \\
\hline & $\mathrm{V}_{2} \mathrm{CO}_{2}+\mathrm{Gr}+\mathrm{Li}$ & 2.779 & -2.537 & 0.891 & 234.123 \\
\hline \multirow[t]{3}{*}{$\mathrm{V}_{2} \mathrm{C}(\mathrm{OH})_{2}$} & mono- $\mathrm{V}_{2} \mathrm{C}(\mathrm{OH})_{2}+\mathrm{Li}$ & - & -0.175 & 0.860 & 331.306 \\
\hline & $\mathrm{bi}-\mathrm{V}_{2} \mathrm{C}(\mathrm{OH})_{2}+\mathrm{Li}$ & 0.395 & -1.336 & 0.878 & 173.077 \\
\hline & $\mathrm{V}_{2} \mathrm{C}(\mathrm{OH})_{2}+\mathrm{Gr}+\mathrm{Li}$ & 2.080 & -0.304 & 0.878 & 232.076 \\
\hline
\end{tabular}

\footnotetext{
${ }^{a}$ For the theoretical gravimetric capacity, the following models are considered. A monolayer is considered to have both its surfaces covered with Li ions, and the ratio of the number of layers for the MXene w.r.t. Li ions is $1: 2$; a bilayer result is given for an infinite multilayer structure, where the ratio of MXene and Li layers is $1: 1$; a heterostructure is also an infinite-layered system which is considered to have an alternating stacking of one layer of $\mathrm{Li}$ ions, one graphene layer, another layer of $\mathrm{Li}$ ions and one MXene layer, where the graphene/MXene/Li ion ratio is $1: 1: 2$. The number of $\mathrm{Li}$ ions in each $\mathrm{Li}$ ion layer in the heterostructures only changes accordingly with the transition metal in the MXene.
} 
latter is more stable than the former for the pristine systems, the former is energetically more favorable for $\mathrm{Li}$ intercalation, which is consistent with previous calculations; ${ }^{43}$ see Table 2. $\mathrm{LiC}_{64}(4 \times 4$ bilayer graphene $)$ in the AA configuration is energetically favorable to accommodate single Li between bilayers, while $\mathrm{Li}$ atoms will not bind at all in the $\mathrm{AB}$ stacked bilayer configuration. However, the magnitude of the binding energy generally is small as compared to the heterostructure due to the strong interaction of $\mathrm{Li}$ with the $\mathrm{M}_{2} \mathrm{CO}_{2}$ layer.

Our results can be summarized as follows: (1) all the systems related to $\mathrm{Sc}_{2} \mathrm{CO}_{2}$ experience severe structural distortion upon $\mathrm{Li}$ interactions. Two or three of the $\mathrm{C}$ atoms in the $\mathrm{Sc}_{2} \mathrm{CO}_{2}$ move towards each other and show the tendency to cluster. Therefore, this type of system is unstable for $\mathrm{Li}$ intercalation. (2) The binding of a $\mathrm{Li}$ atom on mono- $\mathrm{M}_{2} \mathrm{C}(\mathrm{OH})_{2}$ is not favorable. This can be attributed to the Coulomb repulsion between positively charged Li ions and $\mathrm{H}$ atoms. (3) When going from mono- to bi$\mathrm{M}_{2} \mathrm{C}(\mathrm{OH})_{2}+\mathrm{Li}$, Li adsorption is made stable again through the van der Waals interaction that competes with foregoing repulsive interaction. (4) Mono- $\mathrm{M}_{2} \mathrm{CO}_{2}+\mathrm{Li}$, bi- $\mathrm{M}_{2} \mathrm{CX}_{2}+\mathrm{Li}$ and $\mathrm{M}_{2} \mathrm{CX}_{2}$ $+\mathrm{Gr}+\mathrm{Li}$ exhibit the strongest adsorption for $\mathrm{Li}$ atoms. The calculated $E_{\mathrm{b}}^{\mathrm{Li}}$ value at the largest binding energy site is $-1.87 \mathrm{eV}$ per atom for the mono- $\mathrm{Ti}_{2} \mathrm{CO}_{2}$ and $-2.97 \mathrm{eV}$ per atom for the mono $-\mathrm{V}_{2} \mathrm{CO}_{2}$. In the case of $\mathrm{M}_{2} \mathrm{CX}_{2}+\mathrm{Gr}+\mathrm{Li}$, we observed that $E_{\mathrm{b}}^{\mathrm{Li}}$ slightly decreases for $\mathrm{M}=\mathrm{Ti}$ and $\mathrm{V}$ and $\mathrm{X}=\mathrm{O}$. This may be correlated with the reduced van der Waals interaction with respect to the pristine bilayers due to the increase in interlayer separation. The binding energy of the Li atom on the O-terminated MXene monolayer is stronger than that on the $\mathrm{OH}^{-}$ terminated MXene monolayer. In the former (latter), the $\mathrm{O}(\mathrm{H})$ atom carries a net negative (positive) charge. Since the Li atom is positively charged, it is repelled (attracted) by the $\mathrm{H}(\mathrm{O})$ atom, giving rise to different binding energies. A similar argument can be applied to MXene and MXene-graphene bilayers. Another factor that determines the value of the binding energy is the amount of charge transfer from $\mathrm{Li}$ to the host system. For instance, the $\mathrm{Li}$ atom binds more strongly to the $\mathrm{V}_{2} \mathrm{CO}_{2}$ monolayer as compared to the $\mathrm{Ti}_{2} \mathrm{CO}_{2}$ monolayer since we have a larger charge transfer in the $\mathrm{V}_{2} \mathrm{CO}_{2}$ monolayer, giving rise to stronger ionic interaction in $\mathrm{V}_{2} \mathrm{CO}_{2}$ based systems. This is correlated with the fact that $\mathrm{V}_{2} \mathrm{CO}_{2}$ has a larger work function than $\mathrm{Ti}_{2} \mathrm{CO}_{2}$, indicating a higher tendency to get electrons from the Li atom. ${ }^{44}$ Since the origin of the binding between the host and the $\mathrm{Li}$ ion is mainly ionic, the distance of Li from the layer(s) is one of the decisive factors. The smaller the distance, the larger the binding energy. (5) We have identified three promising candidates with a large $\mathrm{Li}$ atom adsorption energy, namely $\mathrm{Sc}_{2} \mathrm{C}(\mathrm{OH})_{2}+\mathrm{Gr}+\mathrm{Li}, \mathrm{Ti}_{2} \mathrm{CO}_{2}+\mathrm{Gr}+\mathrm{Li}$ and $\mathrm{V}_{2} \mathrm{CO}_{2}+\mathrm{Gr}+$ $\mathrm{Li}$. Therefore, for the rest of the paper, we will focus on these three systems and will study the kinetics of Li diffusion.

\subsection{Effect of $\mathrm{Li}$ concentration}

As a next step, we investigated the effect of $\mathrm{Li}$ ion concentration on the physical properties of $\mathrm{M}_{2} \mathrm{CX}_{2}+\mathrm{Gr}+\mathrm{Li}$ heterostructures. Here, the concentration is defined as the ratio of the number of $\mathrm{Li}$ atoms and the number of formula units of $\mathrm{M}_{2} \mathrm{CX}_{2}$ in the heterostructures (e.g. 100\% corresponds to one $\mathrm{Li}$ atom for each formula unit). Fig. 4(a) shows the variation of the average $E_{\mathrm{b}}^{\mathrm{Li}}$ as a function of concentration of $\mathrm{Li}$ ions (i.e. $x$ ). As the number of intercalated $\mathrm{Li}$ ions increases, the average $E_{\mathrm{b}}^{\mathrm{Li}}$ decreases gradually. The reduction in binding energy is due to two main factors; one is the weak electrostatic attraction between the $\mathrm{M}_{2} \mathrm{CX}_{2}+\mathrm{Gr}$ host and the $\mathrm{Li}$ cations, and the other one is the enhanced $\mathrm{Li}-\mathrm{Li}$ repulsion at high $\mathrm{Li}$ concentrations. The former is correlated with the reduction of charge transfer from the $\mathrm{Li}$ atom to the $\mathrm{M}_{2} \mathrm{CX}_{2}+\mathrm{Gr}$ complex at high concentrations, as shown in Fig. 4(b). Similarly, the latter is due to the reduction of interatomic distances between positively charged Li ions. Above a critical concentration value, namely $80 \%, E_{\mathrm{b}}^{\mathrm{Li}}$ becomes positive for $\mathrm{Sc}_{2} \mathrm{C}(\mathrm{OH})_{2}+\mathrm{Gr}+\mathrm{Li}$, and the system becomes energetically unstable for further $\mathrm{Li}$ insertion. $E_{\mathrm{b}}^{\mathrm{Li}}$ is always negative for $\mathrm{Ti}_{2} \mathrm{CO}_{2}+\mathrm{Gr}+\mathrm{Li}$ and $\mathrm{V}_{2} \mathrm{CO}_{2}+\mathrm{Gr}+\mathrm{Li}$, suggesting that these heterostructures are stable against Li intercalation, and thus we can safely disregard the phase separation into individual monolayers and bulk $\mathrm{Li}$ at high concentrations. In other words, the $\mathrm{Ti}_{2} \mathrm{CO}_{2}+\mathrm{Gr}+\mathrm{Li}$ and $\mathrm{V}_{2} \mathrm{CO}_{2}+\mathrm{Gr}+\mathrm{Li}$ structures are highly stable even for high $\mathrm{Li}$ concentrations. For $\mathrm{V}_{2} \mathrm{CO}_{2}+\mathrm{Gr}+\mathrm{Li}$ $\left(\mathrm{Ti}_{2} \mathrm{CO}_{2}+\mathrm{Gr}+\mathrm{Li}\right), E_{\mathrm{b}}^{\mathrm{Li}}$ may vary by about $1(0.5) \mathrm{eV}$ as a function of $\mathrm{Li}$ concentration. Recently, Sun et al. reported that $\mathrm{V}_{2} \mathrm{CO}_{2}$ undergoes a reversible structural transformation during the adsorption of $\mathrm{Li}^{45}$ We also checked the possibility of such structural transformation for the $\mathrm{V}_{2} \mathrm{CO}_{2}+\mathrm{Gr}$ bilayer and we found that the presence of graphene prevents the transformation of $\mathrm{V}_{2} \mathrm{CO}_{2}$. Our results clearly demonstrated that $\mathrm{Ti}_{2} \mathrm{CO}_{2}+\mathrm{Gr}+\mathrm{Li}$ and $\mathrm{V}_{2} \mathrm{CO}_{2}+\mathrm{Gr}+\mathrm{Li}$ can be utilized as an anode material for high capacity Li ion batteries. (a) Binding energy per Li atom

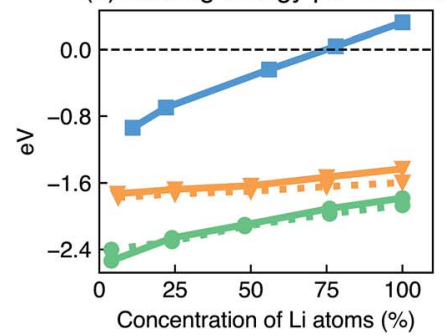

(b) Charge transfer per Li atom

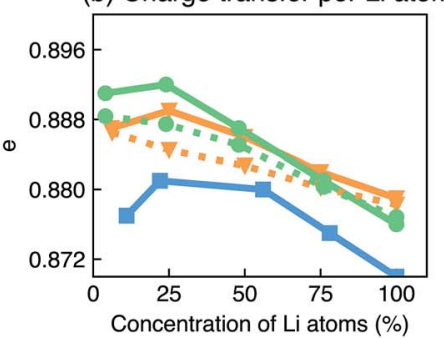

(c) Voltage

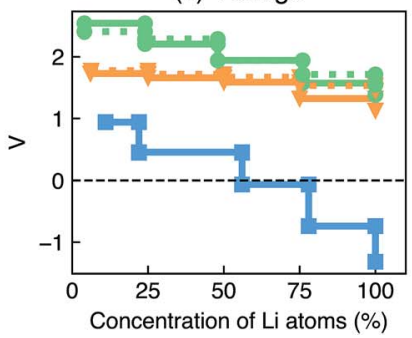

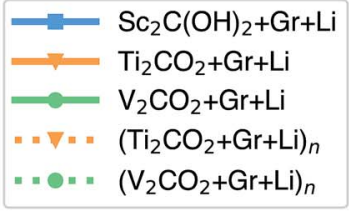

$="-=\left(\mathrm{V}_{2} \mathrm{CO}_{2}+\mathrm{Gr}+\mathrm{Li}\right)_{n}$

Fig. 4 The average binding energy (a), the average charge transfer (b) of Li atoms, and the voltage profile of the $\mathrm{M}_{2} \mathrm{CX}_{2}+\mathrm{Gr}$ heterostructure as a function of Li concentration. Structures with $n$ subscript stand for their infinite-layered nanocomposites. 
Another important point is how the structural stability of $\mathrm{Ti}_{2} \mathrm{CO}_{2}+\mathrm{Gr}+\mathrm{Li}$ and $\mathrm{V}_{2} \mathrm{CO}_{2}+\mathrm{Gr}+\mathrm{Li}$ is affected as the $\mathrm{Li}$ ion concentration is increased. We found that an increase in the number of Li ions leads to a small expansion, i.e. less than $1 \%$, in the in-plane lattice constants. For instance, the in-plane lattice constant of $\mathrm{V}_{2} \mathrm{CO}_{2}+\mathrm{Gr}+\mathrm{Li}$ changed from $2.923 \AA$ at no $\mathrm{Li}$ atom to $2.938 \AA$ at full coverage, and that of $\mathrm{Ti}_{2} \mathrm{CO}_{2}+\mathrm{Gr}+\mathrm{Li}$ first shrinks from $3.050 \AA$ at no $\mathrm{Li}$ atom to $3.047 \AA$ at $50 \%$ coverage, and then it expands to $3.049 \AA$ at full coverage. Besides, we did not observe any severe lengthening of the surface $\mathrm{Ti} / \mathrm{V}-\mathrm{O}$ bonds and shortening of $\mathrm{Li}-\mathrm{O}$ bonds for both $\mathrm{Ti}_{2} \mathrm{CO}_{2}+\mathrm{Gr}+\mathrm{Li}$ and $\mathrm{V}_{2} \mathrm{CO}_{2}+\mathrm{Gr}+\mathrm{Li}$ heterostructures. For instance, the Li-O bond length decreases by at most $3 \%$ with increasing $\mathrm{Li}$ concentration. It was also found that $\mathrm{Li}$ intercalation slightly increases at low $\mathrm{Li}$ concentrations and later reduces the interlayer separation for high Li concentrations. The calculated interlayer separation suggests that we can have at most a $0.5 \AA$ expansion as a result of Li intercalation. These results clearly show that these layered $\mathrm{M}_{2} \mathrm{CX}_{2}+\mathrm{Gr}$ heterostructures possess a reversible reaction process, which is necessary for rechargeable ion batteries and thus they can effectively overcome the volume expansion problem faced by present day electrode materials. However, $\mathrm{Sc}_{2} \mathrm{C}(\mathrm{OH})_{2}+\mathrm{Gr}$ is unstable against Li loading at higher concentrations.

In Table 2, we also present theoretical gravimetric capacities. Compared to MXene bilayers, MXene $+\mathrm{Gr}$ heterostructures possess larger capacity, indicating the advantage of the former system over the latter one. The $\mathrm{Ti}_{2} \mathrm{CO}_{2}-\mathrm{Gr}$ bilayer has the highest gravimetric capacity due to its light formula unit.

Stability is the most important part when investigating newly proposed materials. However, for two individually stable 2D materials forming a vertical heterostructure which are held together by vdW interactions, which are weak in nature, we do not expect that the stability of the whole system will be affected too much. To check the stability of $\mathrm{Ti}_{2} \mathrm{CO}_{2}$-graphene with full coverage of $\mathrm{Li}$ in between, we performed ab initio molecular dynamics simulation. We selected temperatures 100 and $300 \mathrm{~K}$ to see whether small perturbations will induce any structural transformation. We found that the system is stable at both temperatures for 6 ps without any structural deformation.

\subsection{Electrochemical properties}

In order to gain insight into the electrochemical properties of the $\mathrm{Li}$ intercalation process into the $\mathrm{M}_{2} \mathrm{CX}_{2}+\mathrm{Gr}$ heterostructure, the open-circuit-voltage was obtained by calculating the averaged half cell voltage over a range of metal ion concentrations $x$, where $x_{1} \leq x \leq x_{2}$, using

$$
V \approx \frac{E_{\mathrm{M}_{2} \mathrm{CX}_{2}+\mathrm{Gr}+x_{1} \mathrm{Li}}-E_{\mathrm{M}_{2} \mathrm{CX}_{2}+\mathrm{Gr}+x_{2} \mathrm{Li}}+\left(x_{2}-x_{1}\right) E_{\mathrm{Li}}}{\left(x_{2}-x_{1}\right) e}
$$

where $E_{\mathrm{M}_{2} \mathrm{CX}_{2}+\mathrm{Gr}+\mathrm{Li}_{x_{1}}}$ and $E_{\mathrm{M}_{2} \mathrm{CX}_{2}+\mathrm{Gr}+\mathrm{Li}_{x_{2}}}$ are the total energies of the $\mathrm{M}_{2} \mathrm{CX}_{2}+\mathrm{Gr}$ heterostructure with $x_{1}$ and $x_{2} \mathrm{Li}$ intercalated, respectively. $E_{\mathrm{Li}}$ is the total energy of bulk bcc Li. This simple formula gives the voltage difference between two Li concentrations (i.e. $x_{1}$ and $x_{2}$ ). First of all, our calculations show that the calculated voltage for $\mathrm{Li}$ intercalation decreases with increasing
Li ion concentration, as clearly seen in Fig. 4(c). The calculated average voltage corresponding to $\mathrm{Sc}_{2} \mathrm{C}(\mathrm{OH})_{2}+\mathrm{Gr}+\mathrm{Li}$ is negative for $\mathrm{Li}$ ion concentration $x$ larger than $55 \%$. As mentioned above, a phase transition should be expected for concentrations larger than this critical value. Our results are consistent with a recent study reporting that $\mathrm{H}$ and/or $\mathrm{OH}$ should be avoided if possible since they result in a lower capacity and negative cell voltage. ${ }^{16,17}$ On the other hand, the available intercalation sites in $\mathrm{Ti}_{2} \mathrm{CO}_{2}+$ $\mathrm{Gr}+\mathrm{Li}$ and $\mathrm{V}_{2} \mathrm{CO}_{2}+\mathrm{Gr}+\mathrm{Li}$ composites can be fully occupied. As we increase the Li concentration from $x=50 \%$ to $100 \%$, the open-circuit voltage decreases from $1.59(1.94) \mathrm{V}$ to $1.13(1.38) \mathrm{V}$ for $\mathrm{Ti}_{2} \mathrm{CO}_{2}+\mathrm{Gr}+\mathrm{Li}\left(\mathrm{V}_{2} \mathrm{CO}_{2}+\mathrm{Gr}+\mathrm{Li}\right)$. The binding energy change (i.e. $E_{\mathrm{b}}^{\mathrm{Li}}$ ) with the $\mathrm{Li}$ ion concentration can be correlated with the voltage value. Since $\mathrm{V}_{2} \mathrm{CO}_{2}+\mathrm{Gr}+\mathrm{Li}$ has the largest $\mathrm{Li}$ binding energy, the calculated voltage value is also the largest. The calculated average voltage profile is $1.49 \mathrm{~V}$ for $\mathrm{Ti}_{2} \mathrm{CO}_{2}+\mathrm{Gr}+$ $\mathrm{Li}$ and $1.93 \mathrm{~V}$ for $\mathrm{V}_{2} \mathrm{CO}_{2}+\mathrm{Gr}+\mathrm{Li}$, which are higher than those of $\mathrm{Mo}_{2} \mathrm{C},{ }^{14}$ graphite ${ }^{46}$ and $\mathrm{TiO}_{2}$ electrodes ${ }^{47}$ and lower than that of phosphorene. ${ }^{48}$ Experimentally measured maximum voltages for pure $\mathrm{V}_{2} \mathrm{CO}_{2}$ and $\mathrm{Ti}_{2} \mathrm{CO}_{2}$ anodes are $3.0 \mathrm{~V}$ and $2.5 \mathrm{~V}$, respectively. ${ }^{18,49}$ Combining graphene with $\mathrm{V}_{2} \mathrm{CO}_{2}$ or $\mathrm{Ti}_{2} \mathrm{CO}_{2}$ reduces the maximum voltages by about $0.5 \mathrm{~V}$. Approximately $50 \%$ of the capacity of $\mathrm{V}_{2} \mathrm{CO}_{2}+\mathrm{Gr}+\mathrm{Li}\left(\mathrm{Ti}_{2} \mathrm{CO}_{2}+\mathrm{Gr}+\mathrm{Li}\right)$ is intercalated above $2(1.6) \mathrm{V}$, with the rest intercalating at lower voltages. Our results clearly demonstrate that $\mathrm{Ti}_{2} \mathrm{CO}_{2}+\mathrm{Gr}+\mathrm{Li}$ can be exploited in low voltage applications and $\mathrm{V}_{2} \mathrm{CO}_{2}+\mathrm{Gr}+\mathrm{Li}$ is suitable for high charging voltage applications.

When using this type of heterostructure in real battery applications, one needs to build a bulk material from it to maximize the volumetric energy density. This artificially designed bulk material is usually referred to as a nanocomposite. Here, we constructed such a nanocomposite by alternatively stacking MXene and graphene layers. Periodic boundary conditions are used along the $z$-direction, so the number of layers is infinite. It is denoted as $\left(\mathrm{M}_{2} \mathrm{CX}_{2}+\mathrm{Gr}+\mathrm{Li}\right)_{n}$, where $n$ means the infinite number of layers. When forming nanocomposites, the variation of the lattice constant in all cases is small both with or without $\mathrm{Li}$ intercalation, i.e. less than $1 \%$. Similarly, the binding energy, charge transfer and the voltage profiles as a function of the Li concentration are not influenced too much by the formation of nanocomposites. The only exception is for the case of charge transfer, the profile is

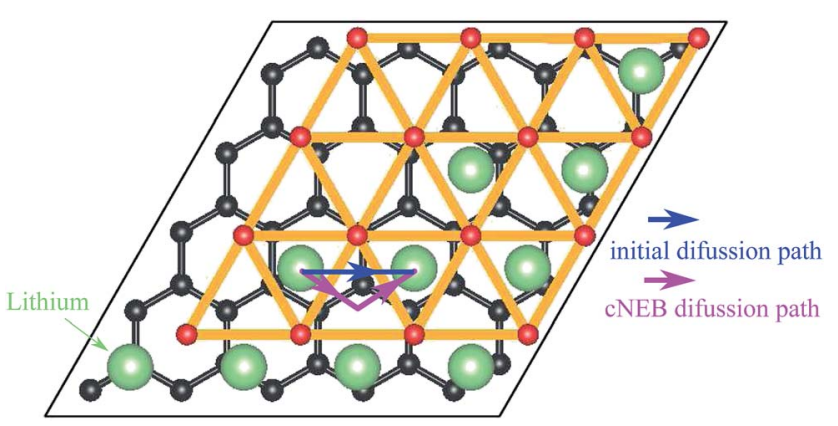

Fig. 5 Initial guessed and final resultant Li diffusion paths in the $\mathrm{Ti}_{2} \mathrm{CO}_{2}$ + Gr heterostructure. 
monotonic in the nanocomposite differing from that for bilayer heterostructures.

\subsection{Diffusion properties}

A low diffusion barrier and high mobility are the requirements of an efficient electrode material. In particular, the mobility of a metal atom on an electrode material is a key factor determining the rate performance during charging and discharging of a battery. Following the thermodynamic consideration of $\mathrm{Li}$ intercalation, we investigated the single $\mathrm{Li}$ kinetics on mono-M $+\mathrm{Li}$, within bi-M $+\mathrm{Li}$ and within $\mathrm{M}+\mathrm{Gr}+\mathrm{Li}$ heterostructures, where $\mathrm{M}=\mathrm{Sc}_{2} \mathrm{C}(\mathrm{OH})_{2}, \mathrm{Ti}_{2} \mathrm{CO}_{2}$ and $\mathrm{V}_{2} \mathrm{CO}_{2}$, by calculating the lowest energy $\mathrm{Li}$ atom diffusion path connecting two adjacent binding sites using the cNEB method; see Fig. 5 and 6. The energy profiles of the paths are shown in Fig. 7. Compared to bilayer systems, Li displays relatively smaller diffusion barriers on pristine monolayers. In other words, the energy barriers of $\mathrm{Li}$

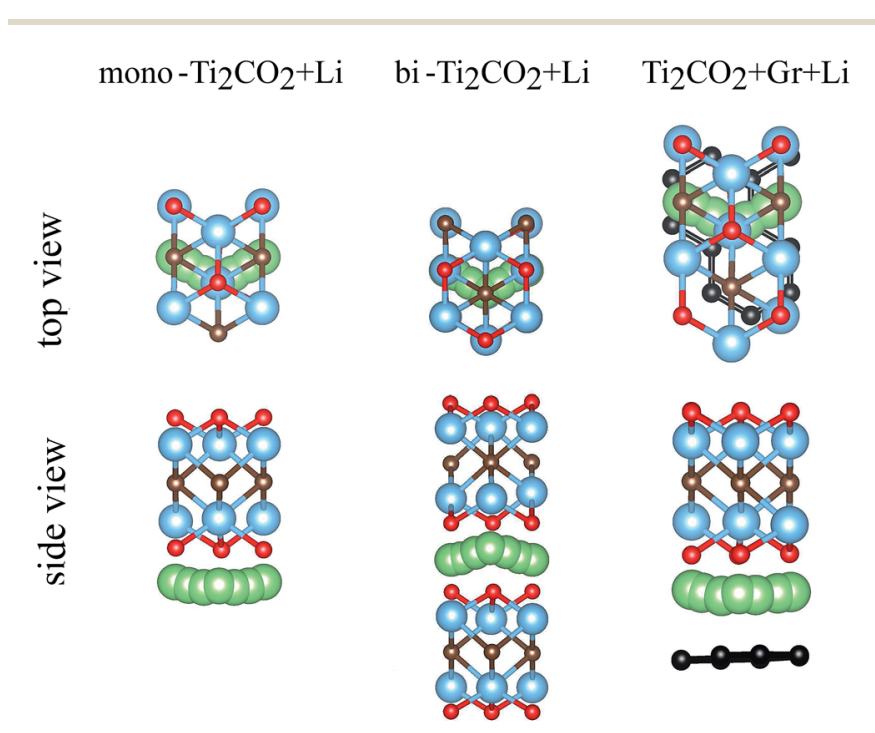

Fig. 6 Top and side views of the lowest energy diffusion path of $\mathrm{Li}$ in $\mathrm{Ti}_{2} \mathrm{CO}_{2}$ related systems. ions in a $\mathrm{M}_{2} \mathrm{CX}_{2}+\mathrm{Gr}+\mathrm{Li}$ heterostructure are always higher than those of the monolayers. This is due to the presence of the geometric constraint in bilayers such that the $\mathrm{Li}$ atom should travel between two surfaces of monolayers instead of moving on top of a single surface as in the case of monolayers. While the energy barrier is calculated to be $0.16 \mathrm{eV}$ on mono- $\mathrm{V}_{2} \mathrm{CO}_{2}+\mathrm{Li}$, it becomes $0.6 \mathrm{eV}$ for bi- $\mathrm{V}_{2} \mathrm{CO}_{2}+\mathrm{Li}$ and $\mathrm{V}_{2} \mathrm{CO}_{2}+\mathrm{Gr}+\mathrm{Li}$ heterostructures. Since the multilayer system has the advantage of having higher capacity than the single monolayer system for a given volume, and also the synthesized $\mathrm{M}_{2} \mathrm{CX}_{2}+\mathrm{Gr}$ will mostly be multilayered, we believe that the monolayer structures represent the lower limit for the energy barriers. However, to obtain realistic kinetic properties we should consider the diffusion of ions between layers not only on isolated monolayers. Another important point is that surface functionalization increases the barrier considerably. ${ }^{50}$ Interestingly, energy barriers for Ti based systems are similar, varying in the range of 0.22-032 eV. Our calculated energy barriers for mono- $\mathrm{Ti}_{2} \mathrm{CO}_{2}+$ $\mathrm{Li}$ are consistent with a recent study. ${ }^{51}$ Regarding the value of diffusion barriers, Li diffusion in $\mathrm{Ti}_{2} \mathrm{CO}_{2}+\mathrm{Gr}$ and that in $\mathrm{V}_{2} \mathrm{CO}_{2}$ $+\mathrm{Gr}$ are quite different. The reason for the large difference in diffusion barrier energies is correlated with the value of the binding energy, interlayer separation and Li-host distances. The binding energies (interlayer distances) are larger (shorter) for the $\mathrm{V}_{2} \mathrm{CO}_{2}$ based systems, making the diffusion of Li atoms more difficult. In addition, in the $\mathrm{V}_{2} \mathrm{CO}_{2}$ based systems, the interlayer separation and distance of $\mathrm{Li}$ from individual layers are short as compared to $\mathrm{Ti}_{2} \mathrm{CO}_{2}$. Due to large binding energies in bilayer $\mathrm{V}_{2} \mathrm{CO}_{2}$ and $\mathrm{V}_{2} \mathrm{CO}_{2}+\mathrm{Gr}$ systems, we have a significant increase in the Li diffusion barrier energies with respect to the monolayer $\mathrm{V}_{2} \mathrm{CO}_{2}$. Energy barriers for Ti-based systems are lower than that of graphite $(0.5 \mathrm{eV})^{52}$ and high-capacity bulk silicon anode materials with a diffusion barrier around $0.57 \mathrm{eV}$ and comparable to commercially used anode materials based on $\mathrm{TiO}_{2}$ which have a barrier of $0.35-0.65 \mathrm{eV},{ }^{53-55}$ suggesting that heterostructures of Ti-based MXenes with graphene are promising candidates for electrode materials in battery applications. The diffusion barriers can be reduced by weakening the
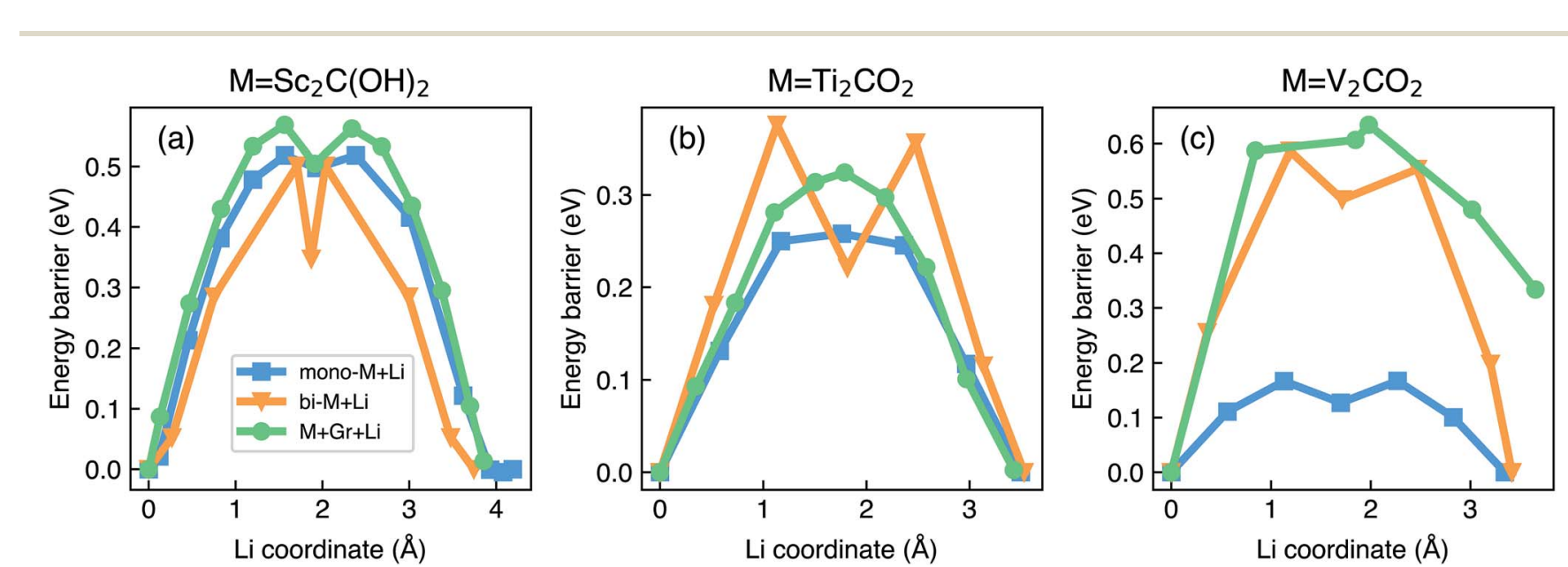

Fig. 7 Energy profiles of $\mathrm{Li}$ diffusion in different systems composed of (a) $\mathrm{Sc}_{2} \mathrm{C}(\mathrm{OH})_{2}$, (b) $\mathrm{Ti}_{2} \mathrm{CO}_{2}$ and (c) $\mathrm{V}_{2} \mathrm{CO}_{2}$ along the lowest energy diffusion path as indicated in Fig. 6. 
interaction of Li ions with the constituent layers. This can be achieved by fabricating pillar structures in which the interlayer distance of graphene and MXenes is enlarged with the help of intercalated molecules. ${ }^{56}$ This method can also improve the storage capacity by multilayer absorption between the layers.

The Li migration barrier is concentration dependent. There are two interactions affecting this diffusion barrier: the interaction of Li with the bilayer and the interaction between the $\mathrm{Li}$ ions. One might expect to see an increasing effect of the latter with increasing concentration. However, since the Li binding is very strong, the diffusion barriers are high even for dilute concentrations as compared to, for instance, $\mathrm{Mo}_{2} \mathrm{C} .{ }^{\mathbf{1 4}}$ Hence the former contribution, i.e. Li interaction with the bilayer, might be a dominating term for all concentrations. In this respect, we performed a barrier calculation for the heavily loaded $\mathrm{Ti}_{2} \mathrm{CO}_{2}+$ $\mathrm{Gr}+\mathrm{Li}$ heterostructure. The calculated barrier height is found to be $0.48 \mathrm{eV}$, which is about $0.15 \mathrm{eV}$ larger than the diffusion barrier of a single Li diffusion within the same bilayer. We believe that this is the upper limit for Li diffusion and we will have barrier heights lower than $0.48 \mathrm{eV}$ for smaller $\mathrm{Li}$ concentrations.

\section{Conclusion}

We carried out first-principles calculations to systematically investigate $\mathrm{Li}$ atom intercalation in MXenes/graphene vertical bilayer heterostructures for Li battery application. Six members of the MXene family were considered to form heterostructures with graphene: $\mathrm{M}_{2} \mathrm{CX}_{2}+\mathrm{Gr}$ (where $\mathrm{M}=\mathrm{Sc}$, Ti, $\mathrm{V}$ and $\mathrm{X}=\mathrm{OH}, \mathrm{O}$ ). The ground state stacking types of bilayers and the strongest binding sites of Li atoms were first determined. The strength of the binding of the bilayer heterostructure is comparable to that of bilayer graphene, and is stronger than that for MXene bilayers. Due to the finite mismatch of the lattice constant of MXenes and graphene, the relative motion of the layers in the heterostructure requires less energy as compared to the other two cases and gives a low friction between them.

We identified two promising heterostructures for $\mathrm{Li}$ intercalation: $\mathrm{Ti}_{2} \mathrm{CO}_{2}+\mathrm{Gr}$ and $\mathrm{V}_{2} \mathrm{CO}_{2}+\mathrm{Gr}$. The stability of the heterostructure upon $\mathrm{Li}$ intercalation is confirmed through: (1) small variations of the structural parameters, e.g. in-plane lattice parameters $(<1 \%)$ and interlayer separation $(<0.5 \AA)$; (2) large negative binding energies of $\mathrm{Li}$ atoms, e.g. larger than that in bilayer graphene; (3) donation of a significant amount of charge by $\mathrm{Li}$ atoms to the host material and their presence in the cationic state. We found that all the possible Li absorption sites can be occupied without compromising stability, namely $100 \% \mathrm{Li}$ intercalation, leading to an average open circuit voltage of $1.49 \mathrm{~V}$ for $\mathrm{Ti}_{2} \mathrm{CO}_{2}+\mathrm{Gr}$ and $1.93 \mathrm{~V}$ for $\mathrm{V}_{2} \mathrm{CO}_{2}+\mathrm{Gr}$. Especially, the $\mathrm{Ti}_{2} \mathrm{CO}_{2}$ MXene offers a compromise between capacity and kinetics since the calculated diffusion barriers are the lowest among the other considered systems and are lower than that of graphene. A balance between the storage capacity and kinetics should be achieved for practical applications when selecting a promising candidate. Due to their lower molecular weights as compared to bare MXene bilayers, MXene + Gr heterostructures offer a higher storage density, and they also have the advantage of good electrical conductivity which is an essential property for a proper operation of a battery.

\section{Conflicts of interest}

There are no conflicts to declare.

\section{Acknowledgements}

This work was supported by the bilateral project between the Scientific and Technological Research Council of Turkey (TUBITAK) and FWO-Flanders, Flemish Science Foundation (FWO-Vl) and the Methusalem foundation of the Flemish government. Computational resources were provided by the TUBITAK ULAKBIM, High Performance and Grid Computing Center (TRGrid e-Infrastructure), and HPC infrastructure of the University of Antwerp (CalcUA) a division of the Flemish Supercomputer Center (VSC), which is funded by the Hercules foundation. We acknowledge the support from the TUBITAK (Grant No. 115F024 and 116F080). Part of this work was supported by the BAGEP Award of the Science Academy.

\section{References}

1 E. Yoo, J. Kim, E. Hosono, H.-s. Zhou, T. Kudo and I. Honma, Nano Lett., 2008, 8, 2277-2282.

2 Y. Jing, Z. Zhou, C. R. Cabrera and Z. Chen, J. Phys. Chem. C, 2013, 117, 25409-25413.

3 E. Yang, H. Ji and Y. Jung, J. Phys. Chem. C, 2015, 119, 2637426380.

4 J. Sun, H.-W. Lee, M. Pasta, H. Yuan, G. Zheng, Y. Sun, Y. Li and Y. Cui, Nat. Nanotechnol., 2015, 10, 980-985.

5 V. V. Kulish, O. I. Malyi, C. Persson and P. Wu, Phys. Chem. Chem. Phys., 2015, 17, 13921-13928.

6 J. Hu, B. Xu, S. A. Yang, S. Guan, C. Ouyang and Y. Yao, ACS Appl. Mater. Interfaces, 2015, 7, 24016-24022.

7 M. Naguib, J. Halim, J. Lu, K. M. Cook, L. Hultman, Y. Gogotsi and M. W. Barsoum, J. Am. Chem. Soc., 2013, 135, 15966-15969.

8 Y. Xie, Y. Dall'Agnese, M. Naguib, Y. Gogotsi, M. W. Barsoum, H. L. Zhuang and P. R. C. Kent, ACS Nano, 2014, 8, 9606-9615.

9 H. Pan, J. Mater. Chem. A, 2015, 3, 21486-21493.

10 D. Wang, Y. Gao, Y. Liu, Y. Gogotsi, X. Meng, G. Chen and Y. Wei, J. Mater. Chem. A, 2017, 5, 24720-24727.

11 D. Wang, Y. Gao, Y. Liu, D. Jin, Y. Gogotsi, X. Meng, F. Du, G. Chen and Y. Wei, J. Phys. Chem. C, 2017, 121, 1302513034.

12 X. Wang, Q. Weng, Y. Yang, Y. Bando and D. Golberg, Chem. Soc. Rev., 2016, 45, 4042-4073.

13 E. Pomerantseva and Y. Gogotsi, Nat. Energy, 2017, 2, 17089. 14 D. Cakir, C. Sevik, O. Gulseren and F. M. Peeters, J. Mater. Chem. A, 2016, 4, 6029-6035.

15 C. E. Ren, M.-Q. Zhao, T. Makaryan, J. Halim, M. Boota, S. Kota, B. Anasori, M. W. Barsoum and Y. Gogotsi, ChemElectroChem, 2016, 3, 689-693. 
16 Y. Xie, M. Naguib, V. N. Mochalin, M. W. Barsoum, Y. Gogotsi, X. Yu, K.-W. Nam, X.-Q. Yang, A. I. Kolesnikov and P. R. C. Kent, J. Am. Chem. Soc., 2014, 136, 6385-6394.

17 Q. Tang, Z. Zhou and P. Shen, J. Am. Chem. Soc., 2012, 134, 16909-16916.

18 M. Naguib, J. Halim, J. Lu, K. M. Cook, L. Hultman, Y. Gogotsi and M. W. Barsoum, J. Am. Chem. Soc., 2013, 135, 15966-15969.

19 C. Eames and M. S. Islam, J. Am. Chem. Soc., 2014, 136, 16270-16276.

20 B. Aissa, A. Ali, K. A. Mahmoud, T. Haddad and M. Nedil, Appl. Phys. Lett., 2016, 109, 043109.

21 G. Kresse and J. Hafner, Phys. Rev. B: Condens. Matter Mater. Phys., 1993, 47, 558-561.

22 G. Kresse and J. Hafner, Phys. Rev. B: Condens. Matter Mater. Phys., 1994, 49, 14251-14269.

23 G. Kresse and J. Furthmüller, Comput. Mater. Sci., 1996, 6, 15-50.

24 G. Kresse and J. Furthmüller, Phys. Rev. B: Condens. Matter Mater. Phys., 1996, 54, 11169-11186.

25 P. E. Blöchl, Phys. Rev. B: Condens. Matter Mater. Phys., 1994, 50, 17953-17979.

26 G. Kresse and D. Joubert, Phys. Rev. B: Condens. Matter Mater. Phys., 1999, 59, 1758-1775.

27 J. P. Perdew, K. Burke and M. Ernzerhof, Phys. Rev. Lett., 1996, 77, 3865-3868.

28 J. P. Perdew, K. Burke and M. Ernzerhof, Phys. Rev. Lett., 1997, 78, 1396.

29 S. Grimme, S. Ehrlich and L. Goerigk, J. Comput. Chem., 2011, 32, 1456-1465.

30 W. Tang, E. Sanville and G. Henkelman, J. Phys.: Condens. Matter, 2009, 21, 084204.

31 E. Sanville, S. D. Kenny, R. Smith and G. Henkelman, J. Comput. Chem., 2007, 28, 899-908.

32 G. Henkelman, A. Arnaldsson and H. Jonsson, Comput. Mater. Sci., 2006, 36, 354-360.

33 M. Yu and D. R. Trinkle, J. Chem. Phys., 2011, 134, 064111.

34 G. Henkelman, B. P. Uberuaga and H. Jansson, J. Chem. Phys., 2000, 113, 9901-9904.

35 G. Henkelman and H. Jansson, J. Chem. Phys., 2000, 113, 9978-9985.
36 E. Mostaani, N. D. Drummond and V. I. Fal'ko, Phys. Rev. Lett., 2015, 115, 115501.

37 G.-C. Guo, D. Wang, X.-L. Wei, Q. Zhang, H. Liu, W.-M. Lau and L.-M. Liu, J. Phys. Chem. Lett., 2015, 6, 5002-5008.

38 A. Samad, M. Noor-A-Alam and Y.-H. Shin, J. Mater. Chem. A, 2016, 4, 14316-14323.

39 E. Lee and K. A. Persson, Nano Lett., 2012, 12, 4624-4628.

40 M. Ashton, R. G. Hennig and S. B. Sinnott, Appl. Phys. Lett., 2016, 108, 023901.

41 E. Joseph and M. Haque, Asian Journal of Physical and Chemical Sciences, 2016, 1, 1-10.

42 C. Kittel, Introduction to Solid State Physics, Wiley, 2004.

43 S. N. Shirodkar and E. Kaxiras, Phys. Rev. B, 2016, 93, 245438.

44 H. A. Tahini, X. Tan and S. C. Smith, Nanoscale, 2017, 9, 7016-7020.

45 D. Sun, Q. Hu, J. Chen, X. Zhang, L. Wang, Q. Wu and A. Zhou, ACS Appl. Mater. Interfaces, 2016, 8, 74-81.

46 K. Persson, Y. Hinuma, Y. S. Meng, A. Van der Ven and G. Ceder, Phys. Rev. B: Condens. Matter Mater. Phys., 2010, 82, 125416.

47 M. V. Koudriachova, N. M. Harrison and S. W. de Leeuw, Solid State Ionics, 2002, 152-153, 189-194.

48 W. Li, Y. Yang, G. Zhang and Y.-W. Zhang, Nano Lett., 2015, 15, 1691-1697.

49 M. Naguib, Electrochem. Commun., 2012, 16, 61.

50 S. Zhao, W. Kang and J. Xue, J. Phys. Chem. C, 2014, 118, 14983-14990.

51 S. Zhao, W. Kang and J. Xue, J. Phys. Chem. C, 2014, 118, 14983-14990.

52 S. Thinius, M. M. Islam, P. Heitjans and T. Bredow, J. Phys. Chem. C, 2014, 118, 2273-2280.

53 S. Lunell, A. Stashans, L. Ojamae, H. Lindstrom and A. Hagfeldt, J. Am. Chem. Soc., 1997, 119, 7374-7380.

54 H. Lindstram, S. Sadergren, A. Solbrand, H. Rensmo, J. Hjelm, A. Hagfeldt and S.-E. Lindquist, J. Phys. Chem. B, 1997, 101, 7710-7716.

55 C. L. Olson, J. Nelson and M. S. Islam, J. Phys. Chem. B, 2006, 110, 9995-10001.

56 J. Luo, W. Zhang, H. Yuan, C. Jin, L. Zhang, H. Huang, C. Liang, Y. Xia, J. Zhang, Y. Gan and X. Tao, ACS Nano, 2017, 11, 2459-2469. 